Part of Journal of Research of the National Bureau of Standards, Volume 34, March 1945

\title{
FREE ENERGIES AND EQUILIBRIA OF ISOMERIZATION OF THE 18 OCTANES ${ }^{1}$
}

\author{
By Edward J. Prosen, Kenneth S. Pitzer, ${ }^{2}$ and Frederick D. Rossini
}

\section{ABSTRACT}

Values of the following thermodynamic properties are presented in tabular and graphical form for the 18 octanes in the ideal gaseous state, for the range $298^{\circ}$ to $1,000^{\circ} \mathrm{K}$ : (a) the standard free energy of isomerization divided by the absolute temperature, $\Delta F^{\circ} / T$; and (b) the relative amounts of the several isomers present in equilibrium with each other.

\section{CONTENTS}

I. Introduction

II. Results in tabular and graphical form

III. Discussion..... 261

IV. References

\section{INTRODUCTION}

Values of the standard free energies of isomerization, and the corresponding equilibrium concentrations, are reported in this paper for the 18 octanes, all in the gaseous state, for the range $298^{\circ}$ to $1,000^{\circ}$ K. These values, similar to those previously presented for the butanes, pentanes, hexanes, and heptanes $[1],{ }^{3}$ have been calculated from the following data:

Heats of isomerization, $\Delta H_{0}^{\circ}$, for the normal paraffin to the branchedchain isomer given in another paper from this laboratory [2].

Entropies of all the octanes, calculated by statistical methods previously described [3,4], which have already been published [5].

Differences in the free energy function between the normal paraffin and a given isomer, which have been claculated by the same methods and for which the values are given in table 1 for the temperatures $298^{\circ}$, $400^{\circ}, 500^{\circ}, 600^{\circ}, 800^{\circ}$, and $1,000^{\circ} \mathrm{K}$.

\footnotetext{
1 This investigation was performed at the National Bureau of Standards jointly by the Thermochemical Laboratory and the American Petroleum Institute Research Project 44 on the "Collection and analysis of data on the properties of hydrocarbons."

2 Professor of Chemistry, University of California, Berkeley, Calif.; consultant to the American Petroleum Institute Research Project 44..

Figures in brackets indicate the literature references at the end of this paper.
} 
TABLE 1.-Values of the difference in the free-energy function between n-octane and its isomers, in the gaseous state

\begin{tabular}{|c|c|c|c|c|c|c|}
\hline \multirow{3}{*}{ Compound (gas) } & \multicolumn{6}{|c|}{$\left(\frac{F^{\circ}-H_{0}^{\circ}}{T}\right)_{n-o 0 t a n e}-\left(\frac{F^{\circ}-H_{0}^{\circ}}{T}\right)_{\text {isoiner }}$} \\
\hline & $298^{\circ} \mathrm{K}$ & $400^{\circ} \mathrm{K}$ & $500^{\circ} \mathrm{K}$ & $600^{\circ} \mathrm{K}$ & $800^{\circ} \mathrm{K}$ & $1,000^{\circ} \mathrm{K}$ \\
\hline & \multicolumn{6}{|c|}{ cal/deg mole } \\
\hline $\begin{array}{l}n \text {-Octane } \\
\text { 2-Methylheptane } \\
\text { 3-Methylheptane } \\
\text { 4-Methylheptane } \\
\text { 3-Ethylhexane } \\
\text { 2, 2-Dimethylhexane } \\
\text { 2, 3-Dimethylhexane } \\
\text { 2, 4-Dimethylhexane } \\
\text { 2, 5-Dimethylhexane } \\
\text { 3, 3-Dimethylhexane } \\
\text { 3, 4-Dimethylhexane } \\
\text { 2-Methyl-3-ethylpentane } \\
\text { 3-Methyl-3-ethylpentane } \\
\text { 2, 2, 3-Trimethylpentane... } \\
\text { 2, 2, 4-Trimethylpentane... } \\
\text { 2, 3, -Trimethylpentane... } \\
\text { 2, 3, 4-Trimethylpentane. } \\
\text { 2, 2, 3-Tetramethylbutane }\end{array}$ & \begin{tabular}{r}
\multicolumn{1}{c}{0} \\
-0.03 \\
1.81 \\
0.11 \\
2.71 \\
-4.44 \\
-1.76 \\
-0.25 \\
-2.17 \\
-2.03 \\
-3.42 \\
-1.94 \\
-3.28 \\
-4.67 \\
-4.67 \\
-3.55 \\
-3.27 \\
-11.75
\end{tabular} & $\begin{array}{r}0 \\
-0.43 \\
1.35 \\
-0.41 \\
1.85 \\
-5.06 \\
-2.22 \\
-1.00 \\
-2.85 \\
-2.85 \\
-3.88 \\
-2.60 \\
-4.03 \\
-5.51 \\
-5.51 \\
-4.27 \\
-4.05 \\
-12.61\end{array}$ & $\begin{array}{r}0 \\
-0.70 \\
1.01 \\
-0.81 \\
1.10 \\
-5.56 \\
-2.55 \\
-1.63 \\
-3.43 \\
-3.50 \\
-4.28 \\
-3.10 \\
-4.67 \\
-6.20 \\
-6.20 \\
-4.88 \\
-4.72 \\
-13.27\end{array}$ & $\begin{array}{r}0 \\
-0.89 \\
.75 \\
-1.14 \\
0.47 \\
-5.96 \\
-2.79 \\
-2.11 \\
-3.88 \\
-3.98 \\
-4.55 \\
-3.45 \\
-5.15 \\
-6.73 \\
-6.73 \\
-5.34 \\
-5.21 \\
-13.67\end{array}$ & $\begin{array}{r}0 \\
-1.00 \\
0.53 \\
-1.44 \\
-0.23 \\
-6.28 \\
-2.93 \\
-2.59 \\
-4.39 \\
-4.45 \\
-4.71 \\
-3.72 \\
-5.50 \\
-7.23 \\
-7.23 \\
-5.76 \\
-5.69 \\
-13.88\end{array}$ & $\begin{array}{r}0 \\
-1.13 \\
0.41 \\
-1.57 \\
-0.57 \\
-6.38 \\
-2.94 \\
-2.69 \\
-4.48 \\
-4.54 \\
-4.75 \\
-3.93 \\
-5.57 \\
-7.33 \\
-7.33 \\
-5.79 \\
-5.80 \\
-13.92\end{array}$ \\
\hline
\end{tabular}

For the isomerization of the normal paraffin to the isoparaffin (normal and iso being indicated by the italic letters $n$ and $i$, respectively),

$$
n-\mathrm{C}_{a} \mathrm{H}_{b} \text { (gas) }=i-\mathrm{C}_{a} \mathrm{H}_{b} \text { (gas), }
$$

$\Delta F^{\circ}$ is the standard free-energy change at a given temperature, with each component in its ideal standard state of unit fugacity, and

$$
\Delta\left(\frac{F^{\circ}-H_{0}^{\circ}}{T}\right)=\left(\frac{F^{\circ}-H_{0}^{\circ}}{T}\right)_{i}-\left(\frac{F^{\circ}-H_{0}^{\circ}}{T}\right)_{n}
$$

where $H$ is the heat content, or enthalpy, and $T$ is the absolute temperature.

But

and

$$
\Delta\left(\frac{F^{\circ}-H_{0}^{\circ}}{T}\right)=\frac{\Delta F^{\circ}}{T}-\frac{\Delta H_{0}^{\circ}}{T}
$$

$$
\frac{\Delta F^{\circ}}{T}=-R \ln K
$$

where $K$ is the equilibrium constant, as defined by Lewis and Randall [6], and $R$ is the gas constant. Then

$$
\frac{\Delta F^{\circ}}{T}=-R \ln K=\frac{\Delta H_{0}^{\circ}}{T}+\Delta\left(\frac{F^{\circ}-H_{0}^{\circ}}{T}\right) .
$$


For the isomerization reaction as given by eq 1 ,

and, for low pressures,

$$
K=f_{i} / f_{n},
$$

$$
K=p_{i} / p_{n},
$$

where $f$ represents fugacity (see reference [6]) and $p$ the partial pressure.

\section{RESULTS IN TABULAR AND GRAPHICAL FORM}

The thermodynamic quantities calculated in this way from the data referred to are given in table 2 . The first two columns give the temperature in centigrade and Kelvin degrees, respectively, with the former rounded off in reference to the latter, the difference being not at all significant here. The succeeding columns give for each isomer values of the following thermodynamic properties: $\Delta F^{\circ} / T$, which is the standard free energy change divided by the absolute temperature for the reaction of isomerization in the gas phase, as expressed by eq $1 ; K$, which is the equilibrium constant, defined by eq 4 and 6 , for the reaction expressed by eq 1 ; and $N$, which is the mole fraction of the given isomer present at equilibrium with all of its other isomers. Strictly, the value of $N$ so calculated is applicable only in the range from zero pressure up to that pressure at which the ratio of fugacity to pressure is still not significantly different for the several isomers. Within this range of pressure, the value of $K$ in table 2 gives the ratio of the amount of the given isomer to the amount of the normal isomer in equilibrium with it in the gas phase. For any two other isomers, the ratio of the corresponding values of $K$ in table 2 gives the ratio of the amounts of those two isomers present at equilibrium in the gas phase with one another.

The limits of uncertainty of the values of $\Delta F^{\circ} / T$ given in table 2 are estimated to be about $\pm 1.5 \mathrm{cal} / \mathrm{deg}$ mole. ${ }^{4}$ This same uncertainty applies to the value of $\Delta F^{\circ} / T$ for the isomerization of any one of the isomers into any other one. From these values, one may easily derive the corresponding uncertainities in the values of the equilibrium constants and the equilibrium concentrations. For example, the ratio

4 Except that the values for 2, 3-dimethylhexane may be uncertain"by several times this amount [2]. 
TABLE 2.-Free energies and equilibria of isomerization of the octanes

\begin{tabular}{|c|c|c|c|c|c|c|c|c|c|c|c|c|c|c|c|c|c|c|c|}
\hline \multirow{2}{*}{\multicolumn{2}{|c|}{ Temperature }} & \multicolumn{18}{|c|}{ Octanes } \\
\hline & & \multicolumn{3}{|c|}{$n$-Octane } & \multicolumn{3}{|c|}{ 2-Methylheptane } & \multicolumn{3}{|c|}{ 3-Methyleptane } & \multicolumn{3}{|c|}{ 4-Methylheptane } & \multicolumn{3}{|c|}{ 3-Ethylhexane } & \multicolumn{3}{|c|}{ 2,2-Dimethylhexane } \\
\hline$t$ & $T$ & $\Delta F^{\circ} / \boldsymbol{T}$ & $K$ & $N$ & $\Delta F^{\circ} / T$ & $K$ & $N$ & $\Delta F^{\circ} / T$ & $K$ & $N$ & $\Delta F^{\circ} / T$ & $K$ & $N$ & $\Delta F^{\circ} / T$ & $K$ & $N$ & $\Delta F^{\circ} / T$ & $K$ & $N$ \\
\hline $\begin{array}{c}{ }^{\circ} \mathrm{C} \\
25 \\
(127) \\
(227) \\
(327) \\
(527) \\
(727)\end{array}$ & $\begin{array}{l}{ }^{\circ} \mathrm{K} \\
298.16 \\
400 \\
500 \\
600 \\
800 \\
1000\end{array}$ & $\begin{array}{c}\text { cal/deg } \\
\text { mole } \\
0 \\
0 \\
0 \\
0 \\
0 \\
0\end{array}$ & $\begin{array}{l}1 \\
1 \\
1 \\
1 \\
1 \\
1 \\
1\end{array}$ & $\begin{array}{l}0.015 \\
.040 \\
.069 \\
.097 \\
.13 \\
.15\end{array}$ & $\begin{array}{c}\text { cal/deg } \\
\text { mole } \\
-3.63 \\
-2.30 \\
-1.48 \\
-0.93 \\
-.36 \\
.04\end{array}$ & $\begin{array}{l}6.21 \\
3.18 \\
2.11 \\
1.60 \\
1.20 \\
0.98\end{array}$ & $\begin{array}{l}0.091 \\
.126 \\
.15 \\
.15 \\
.16 \\
.15\end{array}$ & $\begin{array}{c}\text { cal/deg } \\
\text { mole } \\
-2.85 \\
-2.13 \\
-1.63 \\
-1.27 \\
-0.92 \\
-.72\end{array}$ & $\begin{array}{l}4.20 \\
2.92 \\
2.27 \\
1.90 \\
1.59 \\
1.44\end{array}$ & $\begin{array}{l}0.061 \\
.116 \\
.16 \\
.18 \\
.21 \\
.22\end{array}$ & $\begin{array}{r}\text { cal/deg } \\
\text { mole } \\
-0.45 \\
.16 \\
.61 \\
.97 \\
1.31 \\
1.47\end{array}$ & $\begin{array}{r}1.25 \\
.92 \\
.74 \\
.61 \\
.52 \\
.48\end{array}$ & \begin{tabular}{|}
0.018 \\
.037 \\
.051 \\
.059 \\
.069 \\
.073
\end{tabular} & $\begin{array}{r}\text { cal/deg } \\
\text { mole } \\
-0.63 \\
-.30 \\
.14 \\
.56 \\
1.01 \\
1.19\end{array}$ & $\begin{array}{r}1.37 \\
1.16 \\
0.93 \\
.75 \\
.60 \\
.55\end{array}$ & $\begin{array}{l}0.020 \\
.046 \\
.064 \\
.073 \\
.080 \\
.084\end{array}$ & $\begin{array}{r}\text { cal/deg } \\
\text { mole } \\
-5.29 \\
-2.19 \\
-0.24 \\
1.13 \\
2.65 \\
3.48\end{array}$ & $\begin{array}{c}14.3 \\
3.01 \\
1.13 \\
0.57 \\
.26 \\
.17\end{array}$ & $\begin{array}{l}0.21 \\
.12 \\
.078 \\
.055 \\
.035 \\
.027\end{array}$ \\
\hline \multirow{2}{*}{\multicolumn{2}{|c|}{ Temperature }} & \multicolumn{18}{|c|}{ Octanes-Continued } \\
\hline & & \multicolumn{3}{|c|}{ 2,3-Dimethylhexane } & \multicolumn{3}{|c|}{ 2,4-Dimethylhexane } & \multicolumn{3}{|c|}{ 2,5-Dimethylhexane } & \multicolumn{3}{|c|}{ 3,3-Dimethylhexane } & \multicolumn{3}{|c|}{ 3,4-Dimethylhexane } & \multicolumn{3}{|c|}{$\begin{array}{l}\text { 2-Methyl-3-ethyl- } \\
\text { pentane }\end{array}$} \\
\hline$t$ & $T$ & $\Delta F^{\circ} / T$ & $K$ & $N$ & $\Delta F^{\circ} / T$ & $K$ & $N$ & $\Delta F^{\circ} / T$ & $K$ & $N$ & $\Delta F^{\circ} / T$ & $K$ & $N$ & $\Delta F^{\circ} / T$ & $K$ & $N$ & $\Delta F^{\circ} / T$ & $K$ & $N$ \\
\hline $\begin{array}{c}{ }^{\circ} \mathrm{C} \\
25 \\
(127) \\
(227) \\
(327) \\
(527) \\
(727)\end{array}$ & $\begin{array}{l}{ }^{\circ} \mathrm{K} \\
298.16 \\
400 \\
500 \\
600 \\
800 \\
1000\end{array}$ & $\begin{array}{c}\text { cal/deg } \\
\text { mole } \\
0.32 \\
1.14 \\
1.69 \\
2.07 \\
2.39 \\
2.51\end{array}$ & $\begin{array}{r}0.85 \\
.56 \\
.43 \\
.35 \\
.30 \\
.28\end{array}$ & $\begin{array}{r}0.012 \\
.022 \\
.029 \\
.034 \\
.040 \\
.043\end{array}$ & $\begin{array}{c}\text { cal/deg } \\
\text { mole } \\
-4.48 \\
-2.53 \\
-1.19 \\
-0.24 \\
.83 \\
1.28\end{array}$ & $\begin{array}{l}9.53 \\
3.57 \\
1.82 \\
1.12 \\
0.66 \\
.53\end{array}$ & $\begin{array}{l}0.14 \\
.14 \\
.13 \\
.11 \\
.087 \\
.080\end{array}$ & $\begin{array}{c}\text { cal/deg } \\
\text { mole } \\
-5.48 \\
-2.85 \\
-1.13 \\
0.08 \\
1.54 \\
2.20\end{array}$ & $\begin{array}{c}15.8 \\
4.20 \\
1.77 \\
0.96 \\
.46 \\
.33\end{array}$ & $\begin{array}{l}0.23 \\
.17 \\
.12 \\
.093 \\
.061 \\
.050\end{array}$ & \begin{tabular}{|c|} 
cal/deg \\
mole \\
-3.24 \\
-1.08 \\
0.36 \\
1.36 \\
2.49 \\
2.97
\end{tabular} & $\begin{array}{l}5.11 \\
1.73 \\
0.83 \\
.50 \\
.29 \\
.22\end{array}$ & $\begin{array}{r}0.075 \\
.069 \\
.057 \\
.049 \\
.038 \\
.034\end{array}$ & \begin{tabular}{|c|} 
calldeg \\
mole \\
2.78 \\
3.40 \\
3.90 \\
4.23 \\
4.47 \\
4.56
\end{tabular} & $\begin{array}{r}0.25 \\
.18 \\
.14 \\
.12 \\
.11 \\
.10\end{array}$ & $\begin{array}{c}0.0036 \\
.0072 \\
.0097 \\
.012 \\
.014 \\
.015\end{array}$ & \begin{tabular}{|c|} 
cal/deg \\
mole \\
3.18 \\
3.53 \\
3.84 \\
4.07 \\
4.18 \\
4.30
\end{tabular} & $\begin{array}{r}0.20 \\
.17 \\
.15 \\
.13 \\
.12 \\
.12\end{array}$ & $\begin{array}{c}0.0030 \\
.0067 \\
.010 \\
.013 \\
.016 \\
.018\end{array}$ \\
\hline \multirow{2}{*}{\multicolumn{2}{|c|}{ Temperature }} & \multicolumn{18}{|c|}{ Octanes-Continued } \\
\hline & & \multicolumn{3}{|c|}{$\begin{array}{l}\text { 3-Methyl-3-ethyl- } \\
\text { pentane }\end{array}$} & \multicolumn{3}{|c|}{ 2,2,3-Trimethylpentane } & \multicolumn{3}{|c|}{ 2,2,4-Trimethylpentane } & \multicolumn{3}{|c|}{ 2,3,3-Trimethylpentane } & \multicolumn{3}{|c|}{ 2,3,4-Trimethylpentane } & \multicolumn{3}{|c|}{$\begin{array}{l}\text { 2,2,3,3-Tetramethyl- } \\
\text { butane }\end{array}$} \\
\hline$t$ & $T$ & $\Delta F^{\circ} / T$ & $K$ & $N$ & $\Delta F^{\circ} / T$ & $K$ & $N$ & $\Delta F^{\circ} / T$ & $K$ & $N$ & $\Delta F^{\circ} / T$ & $K$ & $N$ & $\Delta F^{\circ} / T$ & $K$ & $N$ & $\Delta F^{\circ} / T$ & $K$ & $N$ \\
\hline $\begin{array}{c}{ }^{\circ} \mathrm{C} \\
25 \\
(127) \\
(227) \\
(327) \\
(527) \\
(727)\end{array}$ & $\begin{array}{l}{ }^{\circ} K \\
298.16 \\
400 \\
500 \\
600 \\
800 \\
1000\end{array}$ & $\begin{array}{c}\text { calldeg } \\
\text { mole } \\
2.11 \\
3.15 \\
3.97 \\
4.57 \\
5.06 \\
5.22\end{array}$ & $\begin{array}{c}0.35 \\
.21 \\
.14 \\
.10 \\
.078 \\
.072\end{array}$ & $\begin{array}{c}0.0051 \\
.0082 \\
.0094 \\
.0097 \\
.010 \\
.011\end{array}$ & $\begin{array}{c}\text { calldeg } \\
\text { mole } \\
-0.16 \\
1.91 \\
3.32 \\
4.33 \\
5.43 \\
5.89\end{array}$ & $\begin{array}{c}1.08 \\
0.38 \\
.19 \\
.11 \\
.065 \\
.052\end{array}$ & $\begin{array}{l}0.016 \\
.015 \\
.013 \\
.011 \\
.0086 \\
.0079\end{array}$ & $\begin{array}{c}\text { cal/deg } \\
\text { mole } \\
-3.38 \\
-0.49 \\
1.40 \\
2.73 \\
4.23 \\
4.93\end{array}$ & $\begin{array}{c}5.48 \\
1.28 \\
0.49 \\
.25 \\
.12 \\
.084\end{array}$ & $\begin{array}{c}0.080 \\
.051 \\
.034 \\
.024 \\
.016 \\
.013\end{array}$ & $\begin{array}{c}\text { calldeg } \\
\text { mole } \\
1.27 \\
2.57 \\
3.52 \\
4.21 \\
4.91 \\
5.11\end{array}$ & $\begin{array}{l}0.53 \\
.27 \\
.17 \\
.12 \\
.085 \\
.076\end{array}$ & $\begin{array}{c}0.0077 \\
.011 \\
.012 \\
.012 \\
.011 \\
.012\end{array}$ & $\begin{array}{c}\text { cal/deg } \\
\text { mole } \\
0.62 \\
2.07 \\
3.14 \\
3.89 \\
4.70 \\
5.01\end{array}$ & $\begin{array}{l}0.73 \\
.35 \\
.21 \\
.14 \\
.094 \\
.080\end{array}$ & $\begin{array}{c}0.011 \\
.014 \\
.014 \\
.014 \\
.012 \\
.012\end{array}$ & $\begin{array}{c}\text { calldeg } \\
\text { mole } \\
2.49 \\
5.71 \\
7.75 \\
9.07 \\
10.43 \\
11.16\end{array}$ & $\begin{array}{l}0.29 \\
.057 \\
.020 \\
.010 \\
.0053 \\
.0036\end{array}$ & $\begin{array}{r}0.0042 \\
.0023 \\
.0014 \\
.0010 \\
.0007 \\
.0006\end{array}$ \\
\hline
\end{tabular}




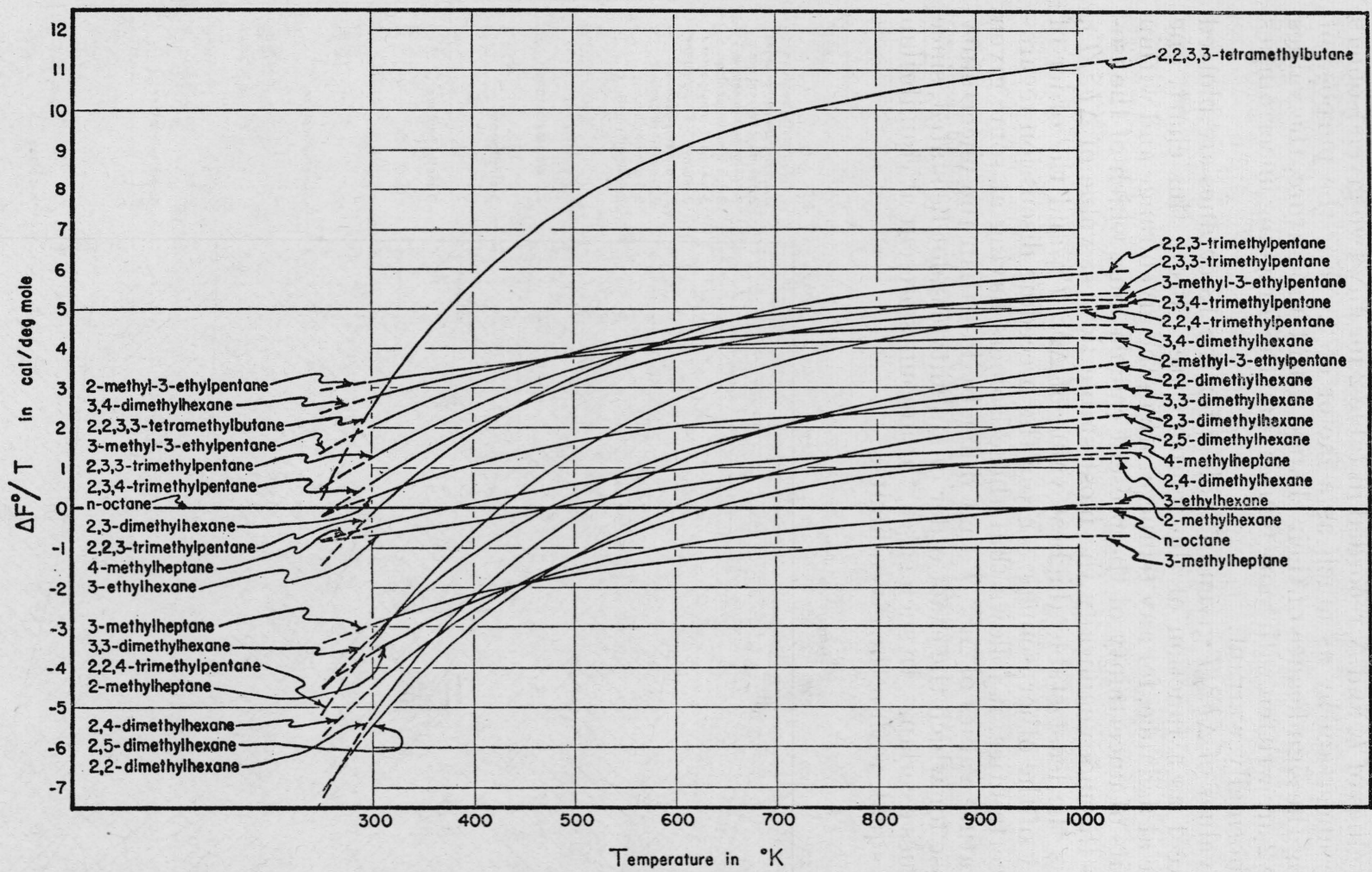

FigURE 1.-Free energy of isomerization of the octanes.

The scale of ordinates gives the value of $\Delta F^{\circ} / T$, in calories per degree mole, for the isomerization $n-\mathrm{C}_{8} \mathrm{H}_{18}$ (gas) $=i-\mathrm{C}_{8} \mathrm{H}_{18}$ (gas).

The seale of abscissas gives the temperature in degrees Kelvin. For octanes having optical isomers, the values are for the racemic mixtures. 
of the values of $K$ and $N$ recorded in table 2 for any two given isomers may be uncertain by as much as a factor of 2 . For the purpose of retaining the significance of their change with temperature, the values in table 2 are written with more figures than the foregoing uncertainties would normally warrant.

The values of $\Delta F^{\circ} / T$ given in table 2 for the 18 octanes are plotted in figure 1 as a function of the temperature. From this chart, one may see at a glance, for any temperature in the given range and within the limits of uncertainty of the present calculations, which of the isomers is thermodynamically the most stable (lowest value of $\Delta F^{\circ} / T$ ), which is the least stable (highest value of $\Delta F^{\circ} / T$ ), and the order of stability of the other isomers. From the preceding discussion regarding uncertainties, it follows that those isomers having at some given temperature values of $\Delta F^{\circ} / T$ that differ by less than the uncertainty are those for which the exact order of stability cannot be stated, since the values overlap. In such cases, the amounts present at equilibrium will be equal, within the given limits.

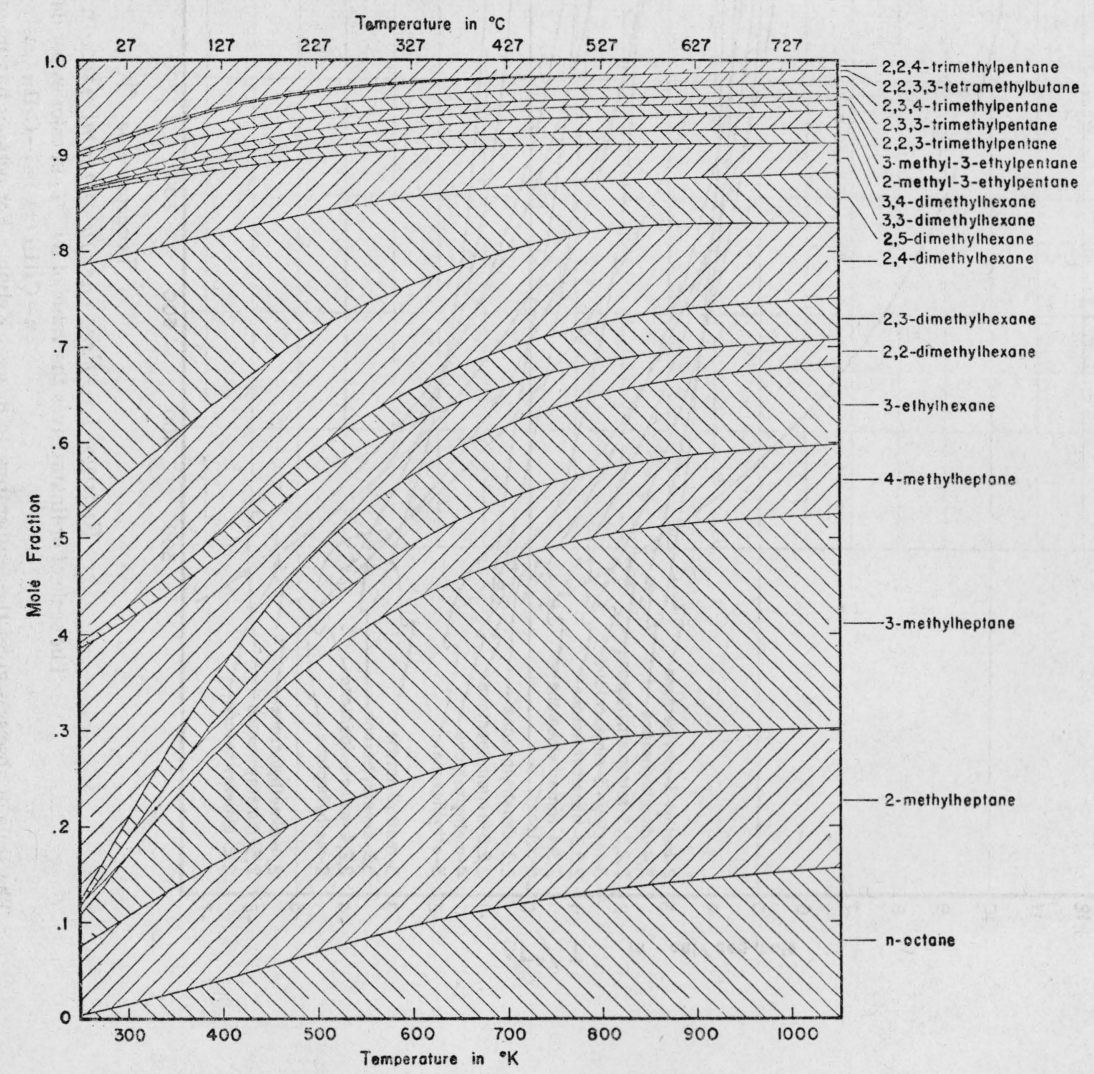

FIGURE 2.-Equilibrium concentrations of the octanes.

The scale of ordinates measures the amount, in mole fraction, and the scale of abscissas gives the temperature in degrees Kelvin and degrees centigrade. The vertical width of a band at a given temperature measures the mole fraction of the given isomer present when at equilibrium with all of its other isomers, in the gas phase. 
In figure 2 are plotted, as a function of the temperature, the amounts, in mole fraction, of each of the isomers present at equilibrium with all its other isomers in the gas phase, as given in table 2. The vertical width of each band gives the mole fraction for that isomer at the selected temperature. The mole fractions of the several isomers are plotted additively, so that their sum is unity at all temperatures.

\section{DISCUSSION}

The values presented in this report for the octanes follow substantially the general conclusions previously drawn for the butanes, pentanes, hexanes, and heptanes, with regard to thermodynamic stability in the gaseous state:

(a) At $25^{\circ} \mathrm{C}$, the normal isomer is among the isomers of lesser stability. Relative to the other isomers, the normal isomer increases in stability with increase in temperature, and at $1,000^{\circ} \mathrm{K}$ is among the most stable of the isomers.

(b) At $25^{\circ} \mathrm{C}, 2,2$-dimethylhexane is among the most stable of the isomers, but it rapidly becomes less stable with increasing temperature and at $1,000^{\circ} \mathrm{K}$ is among the least stable of the isomers.

(c) The more highly branched isomers are among the least stable at the higher temperatures.

\section{REFERENCES}

[1] F. D. Rossini, E. J. Prosen, and K. S. Pitzer, J. Research NBS 27, 529 (1941) RP1440.

[2] E. J. Prosen and F. D. Rossini, J. Research NBS 34, 163 (1945) RP1635.

[3] K. S. Pitzer, J. Chem. Phys. 8, 711 (1940).

[4] K. S. Pitzer, Chem. Rev. 27, 39 (1940).

[5] K. S. Pitzer and D. W. Scott, J. Am. Chem. Soc. 63, 2429 (1941).

[6] G. N. Lewis and M. Randall, Thermodynamics and the Free Energy of Chemical Substances (McGraw-Hill Book Co., Inc., New York, N. Y., 1923).

Washington, August 15, 1944. 